\title{
Microstructure measurements and estimates of entrainment in the Denmark Strait overflow plume
}

\author{
V. Paka ${ }^{1}$, V. Zhurbas ${ }^{2,3}$, B. Rudels ${ }^{4}$, D. Quadfasel ${ }^{5}$, A. Korzh ${ }^{1}$, and D. Delisi ${ }^{6}$ \\ ${ }^{1}$ Shirshov Institute of Oceanology, Atlantic Branch, Prospect Mira 1, 236000 Kaliningrad, Russia \\ ${ }^{2}$ Shirshov Institute of Oceanology, Nakhimovsky Prospect 36, 117997 Moscow, Russia \\ ${ }^{3}$ Marine Systems Institute, Tallinn University of Technology, Akadeemia Road 15a, 12618 Tallinn, Estonia \\ ${ }^{4}$ Finnish Meteorological Institute, P.O. BOX 503, 00101 Helsinki, Finland \\ ${ }^{5}$ Institute of Oceanography, University of Hamburg, Bundesstraße 53, 20146 Hamburg, Germany \\ ${ }^{6}$ NorthWest Research Associates, 4118 148th Ave NE, Redmond, WA 98052, USA
}

Correspondence to: V. Zhurbas (zhurbas@ocean.ru)

Received: 23 May 2013 - Published in Ocean Sci. Discuss.: 3 July 2013

Revised: 11 October 2013 - Accepted: 1 November 2013 - Published: 21 November 2013

\begin{abstract}
To examine processes controlling the entrainment of ambient water into the Denmark Strait overflow (DSO) plume / gravity current, measurements of turbulent dissipation rate were carried out by a quasi-free-falling (tethered) microstructure profiler (MSP). The MSP was specifically designed to collect data on dissipation-scale turbulence and fine thermohaline stratification in an ocean layer located as deep as $3500 \mathrm{~m}$. The task was to perform microstructure measurements in the DSO plume in the lower $300 \mathrm{~m}$ depth interval including the bottom mixed layer and the interfacial layer below the non-turbulent ambient water. The MSP was attached to a Rosette water sampler rack equipped with a SeaBird CTDO and an RD Instruments lowered acoustic Doppler current profiler (LADCP). At a chosen depth, the MSP was remotely released from the rack to perform measurements in a quasi-free-falling mode.

Using the measured vertical profiles of dissipation, the entrainment rate as well as the bottom and interfacial stresses in the DSO plume were estimated at a location $200 \mathrm{~km}$ downstream of the sill at depths up to $1771 \mathrm{~m}$. Dissipation-derived estimates of entrainment were found to be much smaller than bulk estimates of entrainment calculated from the downstream change of the mean properties in the plume, suggesting the lateral stirring due to mesoscale eddies rather than diapycnal mixing as the main contributor to entrainment. Dissipation-derived bottom stress estimates are argued to be roughly one third the magnitude of those derived from log velocity profiles. In the interfacial layer, the Ozmidov scale
\end{abstract}

calculated from turbulence dissipation rate and buoyancy frequency was found to be linearly proportional to the overturning scale extracted from conventional CTD data (the Thorpe scale), with a proportionality constant of 0.76 , and a correlation coefficient of 0.77 .

\section{Introduction}

Dense water formed due to deep convection in the North Atlantic is eventually involved in the global thermohaline overturning circulation called the "global ocean conveyor belt". The Denmark Strait is one of the most geographically confined locations along this entire "conveyor belt" pathway, carrying approximately half of the dense water formed in the Greenland, Iceland, and Norwegian seas in the form of a near-bottom "overflow" current that descends from the sill depth of 600 to $2500 \mathrm{~m}$ at the southern tip of Greenland (Girton and Sanford 2003). The ultimate properties of the deep water mass are therefore determined not only by the direct processes of air-sea interaction that create the initial overflow water, but also by mixing with and entrainment of surrounding fluid during the descent of the density current. For this reason, the location, mechanism, and parameterization of entrainment are of vital importance to the ability to simulate deep water changes in ocean models.

Microstructure measurements in ocean overflows, aimed to estimate kinetic energy dissipation rate, vertical turbulent 
fluxes of momentum/mass, and eventually entrainment, are therefore highly desirable. Johnson et al. (1994a, b) estimated bottom stress on the Mediterranean outflow plume by applying a log-layer model to microstructure measurements of turbulent dissipation rate. Dissipation-derived stress estimates were found to be roughly one third of those obtained in the log-layer from velocity profiles.

Based on microstructure measurements of dissipation profiles in the saline overflow plume in the Arkona Basin in the Baltic Sea, Arneborg et al. (2007) estimated the bottom stress (applying the law of the wall and the balance of dissipation of turbulence kinetic energy and its production in a shear flow) and entrainment (applying a parameterization of diapycnal diffusivity from Osborn, 1980). Umlauf and Arneborg (2009) reexamined data from microstructure measurements in the Arkona Basin overflow plume and, applying a parameterization of diapycnal diffusivity from Shih et al. (2005) (instead of that of Osborn, 1980), arrived at an estimate of entrainment one order of magnitude smaller than that of Arneborg et al. (2007).

Peters and Johns (2005) used regular CTD profiles measured in the Red Sea outflow plume to extract turbulent overturning scales, or Thorpe scales, and equated them to Ozmidov scales. On this basis, interfacial mixing was quantified in terms of estimated turbulent dissipation rates, vertical turbulent salt flux, and interfacial stress.

The entrainment into the overflow across the Greenland Scotland Ridge through the Faroe Bank Channel, the deepest passage in the ridge, was studied by Fer et al. (2010) in dedicated campaign where several sections across the plume were obtained. The dissipation in the overflow plume was estimated by direct turbulence measurements and two regions of intense dissipation were detected, one close to the bottom and one at the interface with a quiet core in between. A strong secondary transverse circulation was found within the plume.

The microstructure measurements of turbulent dissipation rate in oceanic overflows, cited above, have been performed by either expendable dissipation profilers (XDPs) (Lynch and Lueck, 1989) or loosely tethered free-falling microstructure profilers (MSP, Prandke et al., 2000). The standard XDP collects data to a depth of $500 \mathrm{~m}$ and is equipped with a temperature sensor and a sensor measuring one component of vertical shear of horizontal velocity. However, there is a modified $\mathrm{XDP}$ designed to reach depths of $1500 \mathrm{~m}$. In comparison to the XDP, the loosely tethered free-falling microstructure profilers can be equipped with a much richer set of sensors (velocity shear, fast temperature and/or conductivity, standard CTD, and acceleration), collecting data to depths of 200$300 \mathrm{~m}$ (Paka et al., 1999). The main goal of this work was to design, manufacture, and deploy a modified loosely tethered free-falling microstructure profiler capable of collecting data in much deeper layers (up to $3500 \mathrm{~m}$ depth) and use measurements from the profiler to estimate kinetic energy dissipation rate, vertical turbulent fluxes of momentum/mass, and entrainment in the Denmark Strait overflow (DSO) plume.

\section{Instrumentation and methods}

A microstructure profiler (MSP) has to move as a free-falling body with constant velocity to avoid contamination of the fluctuating velocity signal caused by a tight cable connecting the probe to the rolling ship. Two types of MSPs are usually used: free-falling untethered ones, and quasi-free-falling ones. Untethered, free-falling MSPs descend with constant velocity under small negative buoyancy. At a planned lowest depth, a ballast is released, and the MSP floats up to the surface. Some time is then needed for searching and recovering the MSP. Tethered MSPs, which use some kind of tether running loosely from the vessel and following the probe (Lueck et al., 2002), are used to make the measurements more operative. Disturbances due to the tether on measurements from the quasi-free-falling MSP are not disastrous if the profiling depth is not too big and the drift of the ship is not too fast. Otherwise, increasing the drag of the tether and increasing the lateral component of the strain on the tether will create irremovable interference. Our experience is that quasi-freefalling profilers with a tether running from the ship work properly if the profiling depth does not exceed 200-300 m (Paka et al., 1999). For the DSO, the plume depth varies from 700 to $3500 \mathrm{~m}$. Thus, the common scheme of quasifree-falling profiling will not work.

To allow us to use the quasi-free-falling MSP at any depth, we packed the tether in a special magazine inside the MSP. The profiler consists of three main parts: (i) a heavy pressure case with sensors and electronics in front, (ii) a floating module with pressure-resistant glass spheres to compensate for the negative buoyancy of the probe in the middle, and (iii) a magazine for spacing the tether and mounting brushes (hydrodynamic resistance). All three parts comprise a single streamlined body. Only a limited amount of tether $(500 \mathrm{~m}$ of a $4 \mathrm{~mm}$-thick cord) can be put in the magazine. Therefore, to perform measurements at large depths, it is necessary to deliver the profiler to the starting depth without using the tether. We decided that the best carrier for the MSS is a standard Rosette water sampling CTD-LADCP system, which is the main instrument for hydrographic surveys. Joining measurements from a CTD and adding current velocity and microstructure measurements provides the microstructure analysis with necessary bulk parameters of the gravity current and saves expensive ship time. Fig. 1 shows a photo of the measuring system ready for deployment. Fig. 2 explains the principle of releasing the MSP at any chosen depth.

The MSP is equipped with a PNS06 shear probe from ISW Wassermesstechnik, a fast thermistor (model FP07) from GE Thermometics, a 7-ring conductivity cell and high-precision temperature sensor from Idronaut S.r.l., a pressure sensor (model D-25) from PROMPRIBOR (www.prompribor.ru), a 3-component accelerometer (model ADXL203) from Ana$\log$ Devices, Inc., and some auxiliary sensors reserved in the event of accidents. No recording occurs on the MSP from the launch at the ship until the MSP is released from the rack. 


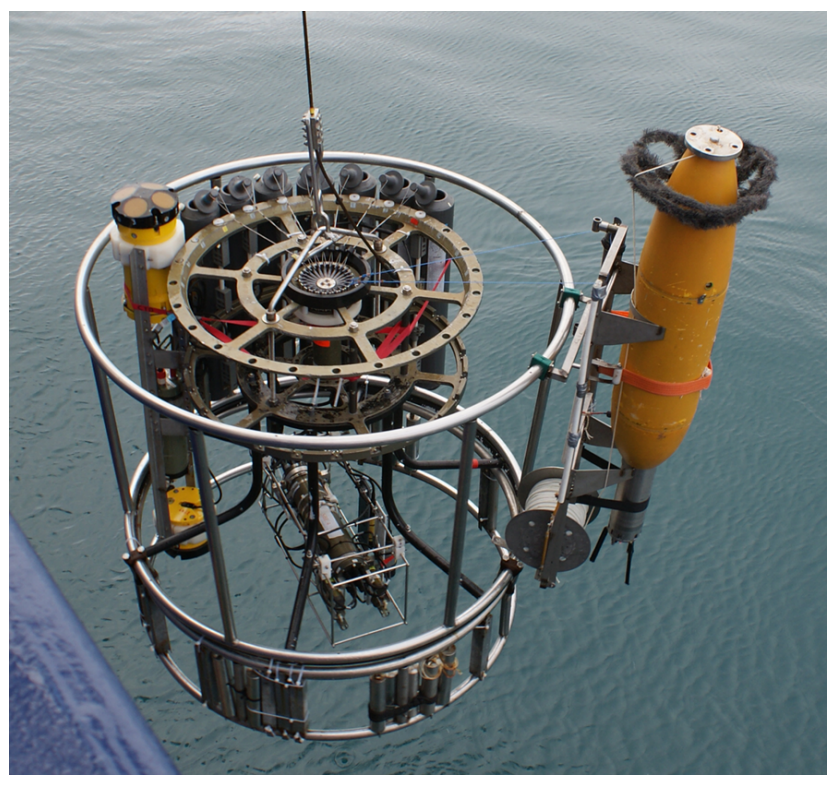

Fig. 1. Photograph of the deployed system. The MSP is the lightcolored object on the right. Also shown are the Rosette water samples, the RDI LADCP, and the SBE CTDO.

Recording is switched on at the moment of releasing the MSP from the rack, as described in Fig. 2. Data are stored on the MSP on an easily replaceable flash memory card.

\section{Data}

The DSO plume was observed during R/V MARIA S. MERIAN cruise MSM21-1b in the summer season 2012. All the measurements presented here were made in two locations close to each other at a distance about $200 \mathrm{~km}$ from the Denmark Sill (Fig. 3). The dates and depths of the combined CTDO/LADCP/MSP measurements are provided in Table 1. All MSP casts began in quiescent ambient water, crossed the interfacial layer, and entered into the adjacent bottom homogeneous layer; only 5 of 17 casts did not reach the sea bed. Due to strong currents, the bottom was firm enough to prevent deep penetration of guarding bars into the ground, so the risk of sensors being broken was not very high; this occurred only once, resulting in a broken shear probe. We considered the risk of breaking sensors justified because obtaining data from the bottom boundary layer is crucial for a full description of the gravity current. The rosette casts were stopped 5 to $10 \mathrm{~m}$ above the bottom, so the background salinity, density, and current velocity profiles did not reach the bottom, though the MSP provided the missed ends of the salinity/density profiles.

An example of the data obtained is presented in Fig. 4 for station 119. The left panel contains plots of full depth background temperature, salinity, density, and dissolved oxygen, measured by the Rosette CTDO. Note the top of the DSO

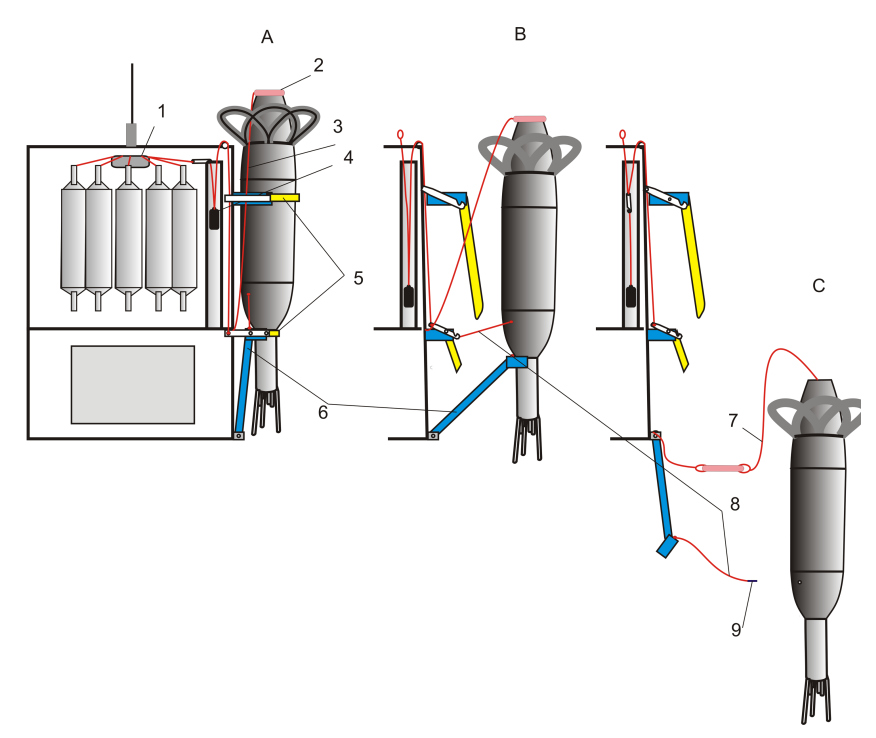

Fig. 2. Principle of releasing the MSP from the rack at a chosen depth. 1 - the trigger assembly on the Rosette rack, 2 - attached load for accelerating the MSP (needed due to the small negative buoyancy of the MSP), 3 - rope fastening the acceleration load to the rack, 4 - trigger, 5 - belts holding the MSP to the rack before release, 6 - turning support, which prevents the MSP from hitting the rack when released, 7 - the main tether, 8 - release cord for the magnet, 9 - magnet, which switches the MSP recording on. (A) shows the configuration before releasing the MSP; in this configuration the MSP is tightly fastened to the rack by two belts; (B) shows the beginning of the release as belts are unlocked by dropping a load, and the MSP moves down and aside due to the joint action of the accelerating load and the turning support; $(\mathbf{C})$ shows the beginning of the free fall as the magnet is pulled out and the MSP recording starts.

around $1260 \mathrm{dBar}$. The shadowed region at the bottom of the plot corresponds to the depths of microstructure profiling. Once the Rosette rack reached the bottom of its drop, it was lifted to the starting point for the MSP data. This starting point was chosen typically at $320 \mathrm{~m}$ above the bottom. In this cast, the start of the MSP profiling is about $110 \mathrm{~m}$ above the top of the DSO interface. The MSP measurements typically started some 15 min after the Rosette rack reached its deepest depth.

The middle panel in Fig. 4 presents current velocity components measured by the LADCP as well as temperature, salinity, and potential density measured by the MSP with maximum spatial resolution. Only light smoothing of the signals was performed to mitigate the noise but to save useful information. There were no special measures against spiking contaminating the salinity and density plots, which was considered inevitable but easily recognized. MSP mounted CTD and microstructure signals along with pressure are plotted versus counts instead of pressure $(1$ count $=0.002 \mathrm{~s})$. The right plot in Fig. 4 shows temperature gradient derived from the fast temperature signal, to characterize the microstructure 


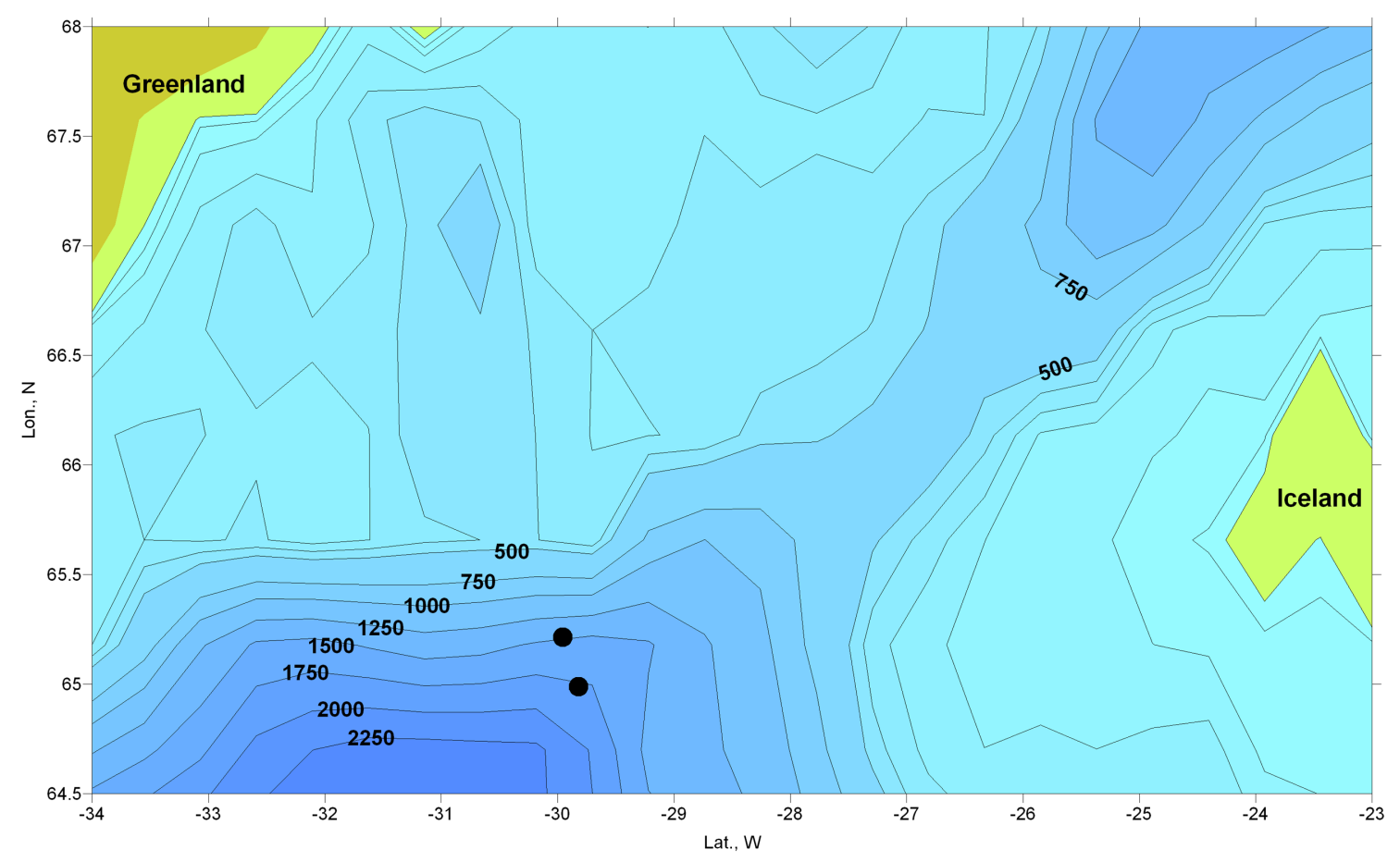

Fig. 3. The research area in 2012. The locations of the stations with MSP/CTDO/LADCP measurements are marked by black circles.

of scalar fields. The two right-most plots are the measured velocity shear signal and the turbulent kinetic energy dissipation rate, $\varepsilon$, calculated from the variance of the vertical current shear fluctuations in the $2-24 \mathrm{~Hz}$ frequency window. The variance was taken as the non-overlapping running mean of 500 counts of the vertical current shear fluctuation squared, which corresponds to vertical averaging over approximately $0.6 \mathrm{~m}$.

The plots presented in Fig. 4 enable us to estimate the data quality of the MSP/CTDO/LADCP system. The background data in Fig. 4 show the presence, bounds, and bulk structure of the DSO plume, and are consistent with numerous previous investigations. The MSP data show the distribution of properties of the microstructure within the layers specified above. The pressure plot versus counts in the middle plot shows a consistent linearity with time until the moment the MSP hits the sea floor; this event is marked by a sharp break in the slope of the pressure signal. The shaded panel space below this moment marks the end of profiling. When the system hits the sea floor, the behavior of the shear velocity signal is expected to be radically changed. It is worthwhile noting that the sharp increase in the shear signal occurred several seconds before reaching the sea floor, which clearly corresponds to a real increase of turbulence dissipation in the bottom boundary layer.

\section{Results}

\subsection{Vertical structure of the overflow plume}

Examples of vertical profiles of magnitude, $|V|=\left(u^{2}+\right.$ $\left.v^{2}\right)^{1 / 2}$, and direction, $\varphi$, of the flow velocity vector, $(u, v)$, salinity, $S$, potential temperature, $\theta$, potential density, $\rho_{\theta}$, Richardson number, $\mathrm{Ri}$, and viscous dissipation rate of kinetic energy of turbulence, $\varepsilon$, are presented in Figs. 5 and 6. The $\mathrm{Ri}$ and $\varepsilon$ are defined as $\mathrm{Ri}=\left(u_{z}^{2}+v_{z}^{2}\right) / N^{2}$ and $\varepsilon=7.5 v\left\langle u_{z}^{\prime 2}\right\rangle$, respectively, where $N^{2}=-\left(g / \rho_{0}\right)\left(\partial \rho_{\theta} / \partial z\right)$ is the buoyancy frequency, $u_{z}, v_{z}, \partial \rho_{\theta} / \partial z$ are vertical gradients of flow velocity components and potential density calculated from LADCP and SeaBird CTD data as the finite differences at vertical increments of $10 \mathrm{~m},\left\langle u_{z}^{\prime 2}\right\rangle$ is the variance of the vertical current shear fluctuations $\left(u_{z}^{\prime}\right)$ calculated from the shear probe on the MSP, $v=(1.79-1.54)$ $10^{-6} \mathrm{~m}^{2} \mathrm{~s}^{-1}$ is the kinematic viscosity in the temperature range of $0-5^{\circ} \mathrm{C}, g=9.81 \mathrm{~m} \mathrm{~s}^{-2}$ is gravitational acceleration, $\rho_{0}=1000 \mathrm{~kg} \mathrm{~m}^{-3}$ is the reference density of water, and the angle brackets denote averaging. In these figures, the vertical coordinate $z$ is increasing upward from $z=0$ at the sea floor.

The gravity flow in the west-southwest direction occupies a near-bottom layer up to $200 \mathrm{~m}$ thick. The main body of the overflow plume consists of a well-developed bottom mixed layer approximately $50-100 \mathrm{~m}$ thick and an interface (gradient) layer with a similar range of thickness (cf. Fig. 5a and b). The maximum value of the gravity flow velocity (up to $1.0 \mathrm{~m}$ 

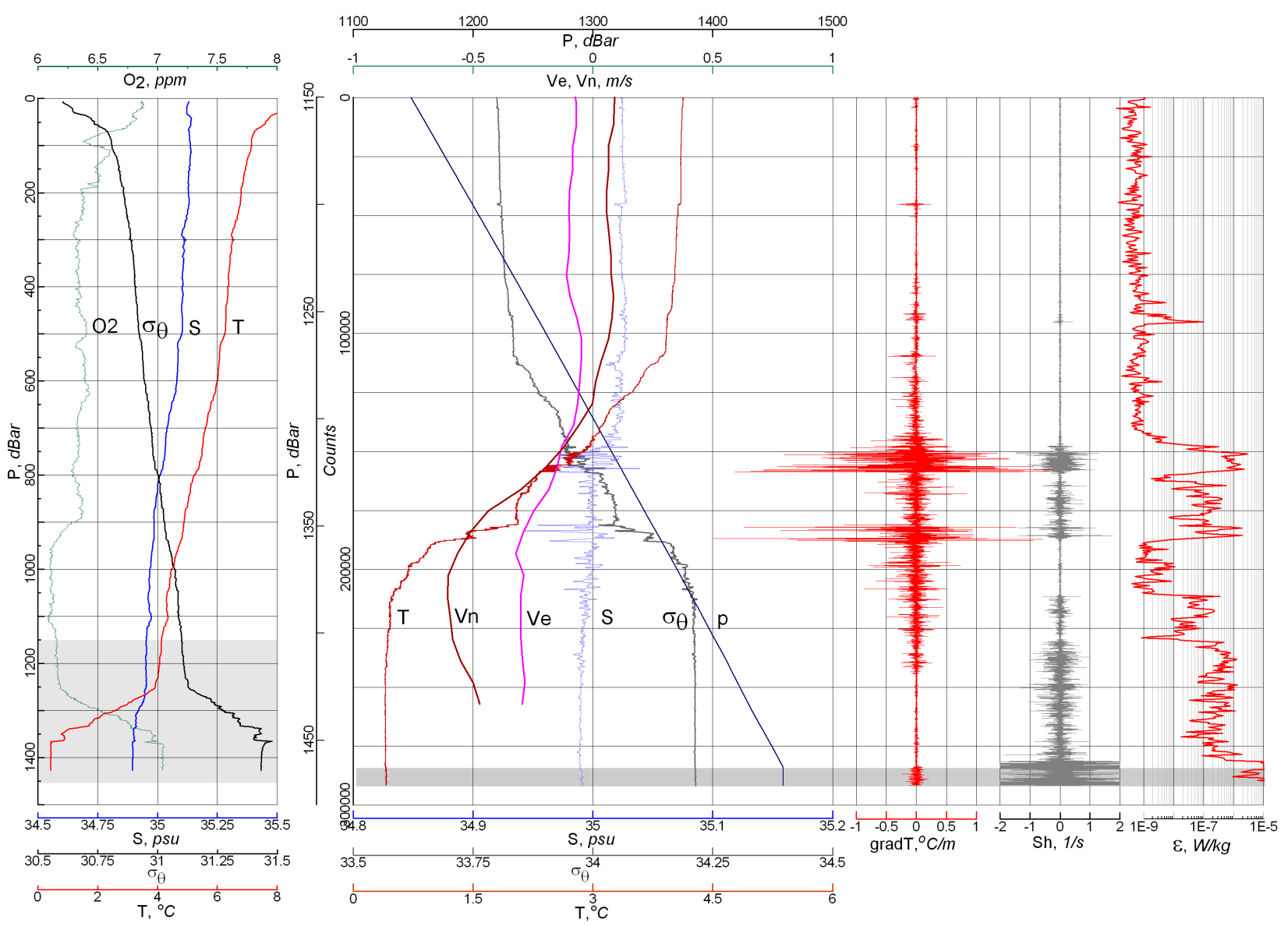

Fig. 4. An example of the MSP/CTDO/LADCP data obtained at station 119 (see text for details).

$\mathrm{s}^{-1}$ ) is observed at the lower edge of the interface layer. A similar location of the velocity maximum at the boundary between the bottom layer and the interfacial layer was reported by Johnson et al. (1994b) from the Mediterranean outflow plume. We believe the coincidence of the depth of the maximum flow velocity with that of the lower edge of the interface layer is an argument in favor of the formation of the bottom mixed layer beneath the gravity flow due to convective overturns. Indeed, there is a simple mechanism common to all gravity currents that would lead to a transport of dense water over light water, namely, a combination of the negative downstream density gradient and the location of the maximum velocity of the gravity current at some distance above the bottom. In this case, the maximum-velocity, dense water layer flowing above the bottom simply overtakes the nearbottom quiescent layer, and convective overturning produces vertical homogeneity of the gravity current underneath. The shear-generated turbulence alone, even though it is highly energetic, has a limited potential to form 'pure' vertical homogeneity, because the higher turbulence will entrain the abovelying light water. One more argument in favor of the convective formation of the bottom mixed layer is a weak hydrostat- ically unstable density stratification frequently observed under gravity currents (Paka et al., 2010; Zhurbas et al., 2011).

Conditions for stratified shear flow instability, $\mathrm{Ri}<0.25$, above the bottom mixed layer where $N^{2}$ is vanishingly small, are frequently satisfied in an upper marginal zone of the interface layer where entrainment takes place (in depth ranges of 180-220, 140-170 and 48-78 m in Figs. 5a, b and 6, respectively), and occasionally in the interior of the "thick" interface layer (e.g., in a depth range of 120-140 m in Fig. 5a).

The thickness of the DSO plume is known to display high variability within 40 to $400 \mathrm{~m}$ (Girton and Sanford, 2003), likely due to mesoscale eddies. For example, at St. 123, located at a sea depth of $1766 \mathrm{~m}$, the thicknesses of the overflow plume / gravity current and the bottom mixed layer are decreased to approximately 80 and $8 \mathrm{~m}$, respectively (Fig. 6).

The dissipation rate $\varepsilon$ has a background noise level of approximately $2 \times 10^{-9} \mathrm{~m}^{2} \mathrm{~s}^{-3}$ above the gravity current and increases by a factor of 10 to 1000 in the gravity current. There is also a rapid increase of $\varepsilon$ some 10 to 100 times as $z \rightarrow+0$, which is observed in cases when the microstructure sonde reaches the sea floor (cf. Fig. 5b, and Fig. 6). This latter increase will be discussed in detail in Sect. 4.3. 
Table 1. Parameters of the overflow plume estimated at different stations.

\begin{tabular}{|c|c|c|c|c|c|c|c|c|c|c|c|}
\hline $\begin{array}{l}\text { Station } \\
\#\end{array}$ & $\begin{array}{c}\text { Date/ } \\
\text { Time, } \\
\text { Jun } 2012\end{array}$ & $\begin{array}{l}\text { Sea } \\
\text { depth, } \\
\text { m }\end{array}$ & $\begin{array}{c}U \\
U_{\max }, \\
\mathrm{ms}^{-1}\end{array}$ & $B, \mathrm{~ms}^{-2}$ & $H, \mathrm{~m}$ & $\begin{array}{c}w_{\mathrm{e}}, 10^{-6}, \\
\mathrm{~ms}^{-1} \\
\text { Eq. (6)/ } \\
\text { Eqs. (1-5) }\end{array}$ & $\begin{array}{c}u_{*} \\
\mathrm{~ms}^{-1} \\
\text { Eq. (11) }\end{array}$ & $\begin{array}{c}u_{* e} \\
\mathrm{~ms}^{-1} \\
\text { Eq. (6) } \\
\text { Eqs. (1-5) }\end{array}$ & $\begin{array}{c}E=\frac{w_{\mathrm{e}}}{U} \\
\text { Eq. (6) } \\
\text { Eqs. (1-5) }\end{array}$ & $F r$ & $\begin{array}{c}C_{\mathrm{d}}= \\
\frac{u_{*}^{2}}{U^{2}}, \frac{u_{*}^{2}}{U_{\max }^{2}}\end{array}$ \\
\hline 119 & 13/05:16 & 1430 & $\begin{array}{l}0.621 \\
0.678\end{array}$ & 0.00361 & 145.2 & $\begin{array}{l}33.9 \\
2.02\end{array}$ & 0.0187 & $\begin{array}{l}4.6 \times 10^{-3} \\
1.1 \times 10^{-3}\end{array}$ & $5.5 \times 10^{-5}$ & $\begin{array}{c}0.86 \\
3.3 \times 10^{-6}\end{array}$ & $\begin{array}{l}0.91 \times 10^{-3} \\
0.76 \times 10^{-3}\end{array}$ \\
\hline 120 & 13/07:19 & 1430 & $\begin{array}{l}0.705 \\
0.763\end{array}$ & 0.00354 & 140.4 & $\begin{array}{l}18.7 \\
1.80\end{array}$ & - & $\begin{array}{l}3.6 \times 10^{-3} \\
1.1 \times 10^{-3}\end{array}$ & $\begin{array}{l}2.7 \times 10^{-5} \\
2.6 \times 10^{-6}\end{array}$ & $\begin{array}{l}1.00 \\
0.11\end{array}$ & - \\
\hline 123 & $13 / 20: 35$ & 1766 & $\begin{array}{l}0.293 \\
0.366\end{array}$ & 0.00168 & 81.8 & $\begin{array}{c}132.0 \\
6.70\end{array}$ & 0.0161 & $\begin{array}{l}6.2 \times 10^{-3} \\
1.4 \times 10^{-3}\end{array}$ & $\begin{array}{l}45.0 \times 10^{-5} \\
22.9 \times 10^{-6}\end{array}$ & 0.79 & $\begin{array}{l}3.0 \times 10^{-3} \\
1.9 \times 10^{-3}\end{array}$ \\
\hline 124 & 13/23:09 & 1771 & $\begin{array}{c}0.293^{*} \\
0.366\end{array}$ & 0.00138 & 95.5 & $\begin{array}{l}80.2 \\
6.64\end{array}$ & 0.0129 & $\begin{array}{l}4.8 \times 10^{-3} \\
1.4 \times 10^{-3}\end{array}$ & $\begin{array}{l}27.0 \times 10^{-5} \\
22.7 \times 10^{-6}\end{array}$ & 0.81 & $\begin{array}{l}1.9 \times 10^{-3} \\
1.2 \times 10^{-3}\end{array}$ \\
\hline 128 & 14/10:28 & 1474 & $\begin{array}{l}0.702 \\
0.624\end{array}$ & 0.00263 & 125.1 & $\begin{array}{l}42.1 \\
3.13\end{array}$ & - & $\begin{array}{l}5.4 \times 10^{-3} \\
1.5 \times 10^{-3}\end{array}$ & $\begin{array}{c}6.0 \times 10^{-5-6} \\
4.5 \times 10\end{array}$ & 1.22 & - \\
\hline 129 & 14/16:05 & 1473 & $\begin{array}{l}0.909 \\
0.954\end{array}$ & 0.00282 & 162.8 & $\begin{array}{l}57.4 \\
3.71\end{array}$ & - & $\begin{array}{l}7.2 \times 10^{-3} \\
1.8 \times 10^{-3}\end{array}$ & $\begin{array}{l}6.3 \times 10^{-5} \\
4.1 \times 10^{-6}\end{array}$ & 1.34 & - \\
\hline 130 & $14 / 18: 22$ & 1473 & $\begin{array}{l}0.903 \\
0.939\end{array}$ & 0.00319 & 154.6 & $\begin{array}{l}30.1 \\
2.86\end{array}$ & - & $\begin{array}{l}5.2 \times 10^{-3} \\
1.6 \times 10^{-3}\end{array}$ & $\begin{array}{l}3.3 \times 10^{-5} \\
3.2 \times 10^{-6}\end{array}$ & 1.29 & - \\
\hline 144 & $16 / 09: 43$ & 1438 & $\begin{array}{l}0.524 \\
0.563\end{array}$ & 0.00297 & 189.3 & $\begin{array}{l}21.2 \\
2.02\end{array}$ & - & $\begin{array}{l}3.3 \times 10^{-3} \\
1.0 \times 10^{-3}\end{array}$ & $\begin{array}{l}4.1 \times 10^{-5} \\
3.9 \times 10^{-6}\end{array}$ & 0.70 & - \\
\hline 145 & $16 / 12: 02$ & 1442 & $\begin{array}{l}0.508 \\
0.596\end{array}$ & 0.00299 & 209.7 & $\begin{array}{l}19.3 \\
1.49\end{array}$ & - & $\begin{array}{l}3.1 \times 10^{-3} \\
0.9 \times 10^{-3}\end{array}$ & $\begin{array}{l}3.8 \times 10^{-5} \\
2.9 \times 10^{-6}\end{array}$ & 0.64 & - \\
\hline 146 & $16 / 15: 16$ & 1443 & $\begin{array}{l}0.347 \\
0.627\end{array}$ & 0.00242 & 210.8 & $\begin{array}{l}34.7 \\
2.16\end{array}$ & - & $\begin{array}{l}3.5 \times 10^{-3} \\
0.9 \times 10^{-3}\end{array}$ & $\begin{array}{c}10.0 \times 10^{-5} \\
6.2 \times 10^{-6}\end{array}$ & 0.49 & - \\
\hline 148 & 16/20:11 & 1454 & - & 0.00274 & 194.3 & $\begin{array}{l}13.2 \\
1.55\end{array}$ & - & - & - & - & - \\
\hline 158 & 18/01:14 & 1439 & $\begin{array}{l}0.374 \\
0.592\end{array}$ & 0.00206 & 139.5 & $\begin{array}{c}5.2 \\
1.35\end{array}$ & 0.0142 & $\begin{array}{l}1.4 \times 10^{-3} \\
0.7 \times 10^{-3}\end{array}$ & $\begin{array}{l}1.4 \times 10^{-5} \\
3.6 \times 10^{-6}\end{array}$ & 0.70 & $\begin{array}{c}1.4 \times 10^{-3} \\
0.58 \times 10^{-3}\end{array}$ \\
\hline 160 & 18/06:07 & 1440 & $\begin{array}{l}0.327 \\
0.414\end{array}$ & 0.00172 & 143.9 & $\begin{array}{c}9.4 \\
1.29\end{array}$ & 0.0115 & $\begin{array}{l}1.8 \times 10^{-3} \\
0.6 \times 10^{-3}\end{array}$ & $\begin{array}{l}2.9 \times 10^{-5} \\
3.9 \times 10^{-6}\end{array}$ & 0.66 & $\begin{array}{c}1.2 \times 10^{-3} \\
0.77 \times 10^{-3}\end{array}$ \\
\hline 178 & 19/19:43 & 1441 & $\begin{array}{l}0.542 \\
0.795\end{array}$ & 0.00280 & 176.1 & $\begin{array}{l}32.0 \\
1.34\end{array}$ & 0.0294 & $\begin{array}{l}4.2 \times 10^{-3} \\
0.9 \times 10^{-3}\end{array}$ & $\begin{array}{l}5.9 \times 10^{-5} \\
2.5 \times 10^{-6}\end{array}$ & 0.77 & $\begin{array}{l}2.9 \times 10^{-3} \\
1.4 \times 10^{-3}\end{array}$ \\
\hline 179 & 19/21:59 & 1440 & $\begin{array}{l}0.640 \\
0.819\end{array}$ & 0.00268 & 179.0 & $\begin{array}{l}35.5 \\
2.55\end{array}$ & 0.0245 & $\begin{array}{l}4.8 \times 10^{-3} \\
1.3 \times 10^{-3}\end{array}$ & $\begin{array}{l}5.6 \times 10^{-5} \\
4.0 \times 10^{-6}\end{array}$ & 0.92 & $\begin{array}{c}1.5 \times 10^{-3} \\
0.89 \times 10^{-3}\end{array}$ \\
\hline 180 & 20/00:22 & 1444 & $\begin{array}{l}0.699 \\
0.853\end{array}$ & 0.00305 & 183.9 & $\begin{array}{l}43.9 \\
2.34\end{array}$ & - & $\begin{array}{l}5.5 \times 10^{-3} \\
1.3 \times 10^{-3}\end{array}$ & $\begin{array}{l}6.3 \times 10^{-5} \\
3.3 \times 10^{-6}\end{array}$ & 0.93 & - \\
\hline 181 & $20 / 02: 43$ & 1445 & $\begin{array}{l}0.724 \\
0.916\end{array}$ & 0.00309 & 178.6 & $\begin{array}{l}36.0 \\
2.01\end{array}$ & - & $\begin{array}{l}5.1 \times 10^{-3} \\
1.2 \times 10^{-3}\end{array}$ & $\begin{array}{l}5.0 \times 10^{-5} \\
2.8 \times 10^{-6}\end{array}$ & 0.97 & - \\
\hline
\end{tabular}

\subsection{Microstructure estimates of entrainment}

Depending on the turbulence intensity parameter in stratified media, $\varepsilon / \nu N^{2}$, the vertical eddy diffusivity of mass $K_{\rho}$ calculated from the measured quantities $\left(\varepsilon, N^{2}\right)$ can be estimated from Shih et al. (2005):

$K_{\rho}=\left\{\begin{array}{l}0.2 \varepsilon / N^{2} \text { for } 7<\varepsilon / v N^{2}<100 \\ 2 v\left(\varepsilon / v N^{2}\right)^{1 / 2} \text { for } \varepsilon / v N^{2}>100\end{array}\right.$.

The parameterization (Eq. 1) comprises results of both laboratory experiments and direct numerical simulations; the moderate turbulence intensity regime $\left(7<\varepsilon / v N^{2}<100\right)$ corresponds to stationary turbulence (Osborn, 1980), while the energetic regime $\left(\varepsilon / v N^{2}>100\right)$ corresponds to growing turbulence (Shih et al., 2005).
An alternative approach to parameterizing $K_{\rho}$ was used by Peters and Bokhorst (2001) in the form

$K_{\rho}=\gamma(\mathrm{Ri}) \varepsilon / N^{2}$,

where $\gamma=R_{\mathrm{f}} /\left(1-R_{\mathrm{f}}\right)$ is the turbulent mixing efficiency, $R_{\mathrm{f}}=\mathrm{Ri} / \mathrm{Pr}_{t}$ is the flux Richardson number, and $\operatorname{Pr}_{t}$ is the turbulent Prandtl number. The mixing efficiency $\gamma=\gamma(\mathrm{Ri})$ is taken as an empirical function of the gradient Richardson number $\mathrm{Ri}$, with asymptotics $\gamma \approx 0.2$ at $\mathrm{Ri} \geq 0.25$ and $\gamma \sim \mathrm{Ri}$ at $\mathrm{Ri} \rightarrow 0$. The parameterization (Eq. 2) seems to be more suitable for geophysical flows than Eq. (1), because the former is based on a stationary balance of turbulent kinetic energy in production-dissipation-buoyancy flux equilibrium suggested by Osborn (1980), while the latter corresponds to unsteady, growing turbulence at $\varepsilon / v N^{2}>100$. However, we 


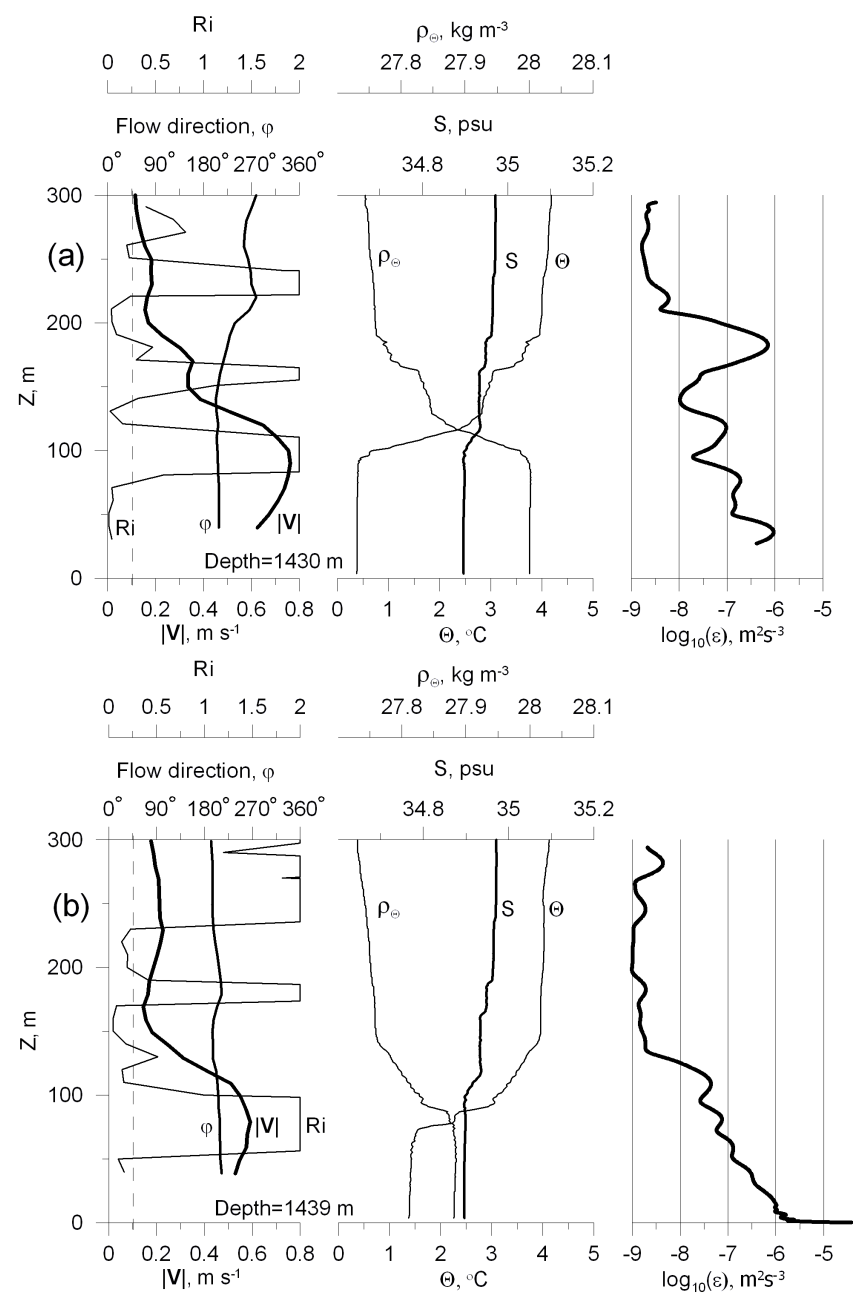

Fig. 5. Vertical profiles of modulus $|V|$ and direction $\varphi$ of current velocity, salinity $S$, potential temperature $\theta$ and density $\rho_{\theta}$, the Richardson number $R i$, and the dissipation rate $\varepsilon$ in the DSO plume at stations (a) 120 and (b) 158.

cannot apply Eq. (2) because we do not possess simultaneous vertical profiles of Ri, $\varepsilon$ and $N^{2}$; as discussed in Sect. 3, the LADCP/CTDO casts used to estimate Ri were taken approximately half an hour before the MSP casts. In such circumstances, it seems worthwhile to calculate $K_{\rho}$ both from the Osborn (1980) formulation $K_{\rho}=0.2 \varepsilon / N^{2}$ and from the Shih et al. (2005) formulation (Eq. 1); the former is used for an upper estimate of eddy diffusivity and the latter for a lower estimate.

The bulk structure of the gravity current can be described by the bulk thickness, $H$, buoyancy jump, $B$, and velocity, $U$, defined following Arneborg et al. (2007) as

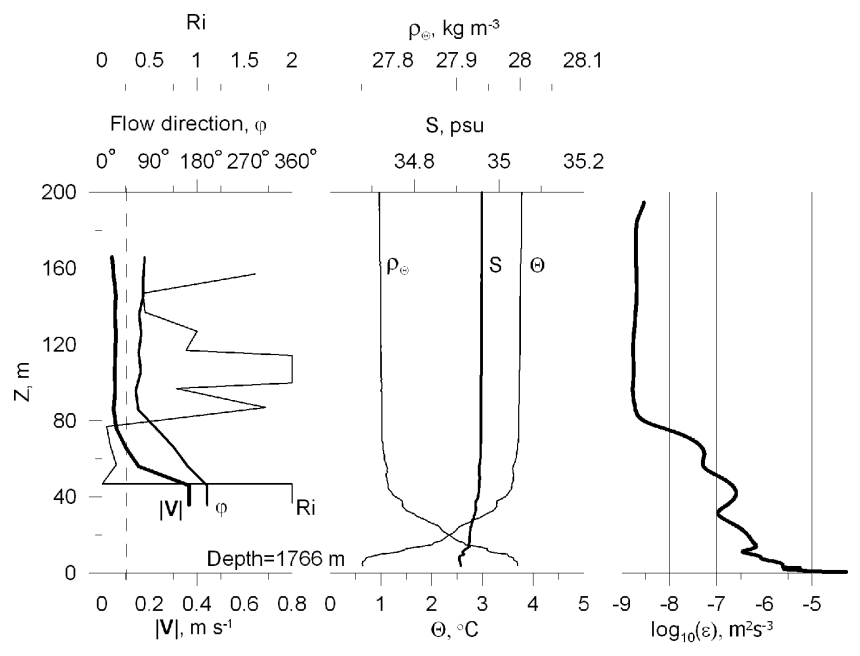

Fig. 6. The same as in Fig. 5, but for St. 123, displaying a relatively thin overflow plume with the bottom mixed layer almost missing.

$$
\begin{aligned}
& B H=\int_{0}^{\infty} g \frac{\rho_{\theta}(z)-\rho_{\theta}(\infty)}{\rho_{0}} \mathrm{~d} z=\int_{0}^{\infty} g^{*} \mathrm{~d} z \\
& \frac{B H^{2}}{2}=\int_{0}^{\infty} g^{*} z \mathrm{~d} z \\
& U=\left(U_{b}^{2}+V_{b}^{2}\right)^{1 / 2}, U_{b} H=\int_{0}^{\infty} u \mathrm{~d} z, V_{b} H=\int_{0}^{\infty} v \mathrm{~d} z
\end{aligned}
$$

The entrainment rate, $w_{\mathrm{e}} \equiv \partial H / \partial t$, can, in view of Eq. (3), be expressed as

$$
w_{\mathrm{e}}=2 \frac{\partial}{\partial t}\left[\int_{0}^{\infty} g^{*} z \mathrm{~d} z / \int_{0}^{\infty} g^{*} \mathrm{~d} z\right]=2 \frac{\partial}{\partial t}\left[\int_{0}^{\infty} g^{*} z \mathrm{~d} z\right] / \int_{0}^{\infty} g^{*} \mathrm{~d} z .
$$

The second equality in Eq. (4) is valid because $\partial(B H) / \partial t=0$ in the course of vertical mixing/entrainment. Evolution of the density profile due to vertical mixing/entrainment is described by the diffusion equation

$\frac{\partial \rho_{\theta}}{\partial t}=-\frac{\partial\left\langle w^{\prime} \rho^{\prime}\right\rangle}{\partial z}=\frac{\partial}{\partial z}\left(K_{\rho} \frac{\partial \rho_{\theta}}{\partial z}\right)$,

and, in view of Eq. (5), Eq. (4) can be transformed to (Arneborg et al., 2007)

$w_{\mathrm{e}}=\frac{2}{B H} \int_{0}^{\infty} \frac{g}{\rho_{0}}\left\langle w^{\prime} \rho^{\prime}\right\rangle \mathrm{d} z=\frac{2}{\mathrm{BH}} \int_{0}^{\infty} K_{\rho} N^{2} \mathrm{~d} z$.

Note that if one ignores the second equation of Eq. (1) for large values of $\varepsilon / \nu \mathrm{N}^{2}$, and focuses on the original Osborn (1980) formulation $K_{\rho}=0.2 \varepsilon / N^{2}$, the entrainment rate $\left(3^{\prime}\right)$ can be expressed as

$$
w_{\mathrm{e}}=0.4 \int_{0}^{\infty} \varepsilon \mathrm{d} z / \int_{0}^{\infty} g^{*} \mathrm{~d} z
$$




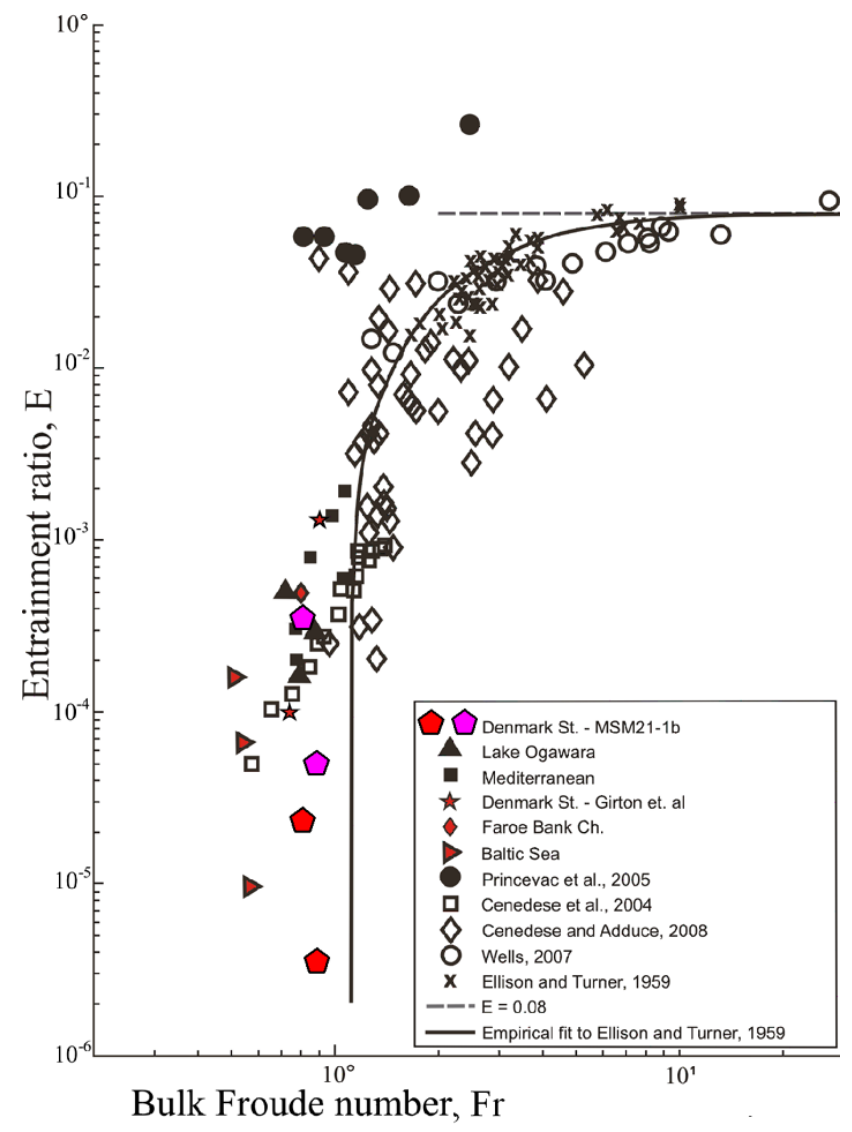

Fig. 7. Measurements of entrainment ratio $E$ plotted as a function of the bulk Froude number Fr (a replica of Fig. 2 by Wells at al. (2010) supplemented with this study data). The data comes from field and laboratory experiments over a wide range of Reynolds numbers. The oceanic data span five location sites: the Mediterranean overflow (Baringer and Price, 1997), Denmark Strait (Girton and Sanford, 2003; this study), Faroe Bank Strait (Mauritzen et al., 2005), the Baltic Sea (Arneborg et al., 2007), and Lake Ogawara (Dallimore et al., 2001). Two red and two magenta pentagons present our estimates of $E$ from Eqs. (7) and (1-6), respectively.

In practice, there is a difficulty in using Eqs. (1) and (6) to calculate entrainment to the gravity current, because the parameterization (Eq. 1) is not valid in the bottom mixed layer where the density stratification is close to neutral and the mixing parameter is expected to be infinitively large $\left(\varepsilon / \nu N^{2} \rightarrow \infty\right)$. To treat this difficulty, one can accept that the buoyancy flux, $K_{\rho} N^{2}$, is linearly growing with $z$ within the bottom mixed layer from $K_{\rho} N^{2}=0$ at $z=0$ to some positive value $\left(K_{\rho} N^{2}\right)_{i}>0$ at the base of the above-lying interfa$\mathrm{cial} / \mathrm{stratified} \mathrm{layer.} \mathrm{Note} \mathrm{that} \mathrm{the} \mathrm{linear} \mathrm{growth} \mathrm{of} \mathrm{the} \mathrm{buoy-}$ ancy flux with $z$, in view of Eq. (5), corresponds to neutral stratification (i.e., $\partial \rho_{\theta} / \partial z=0$ ) in the bottom mixed layer. To estimate $\left(K_{\rho} N^{2}\right)_{i}$, we will take the average value of $K_{\rho} N^{2}$ within the interfacial layer. All the same, Eq. (7) is not applicable within the bottom mixed (uniform density) layer where the buoyancy flux is expected to increase linearly with $z$.

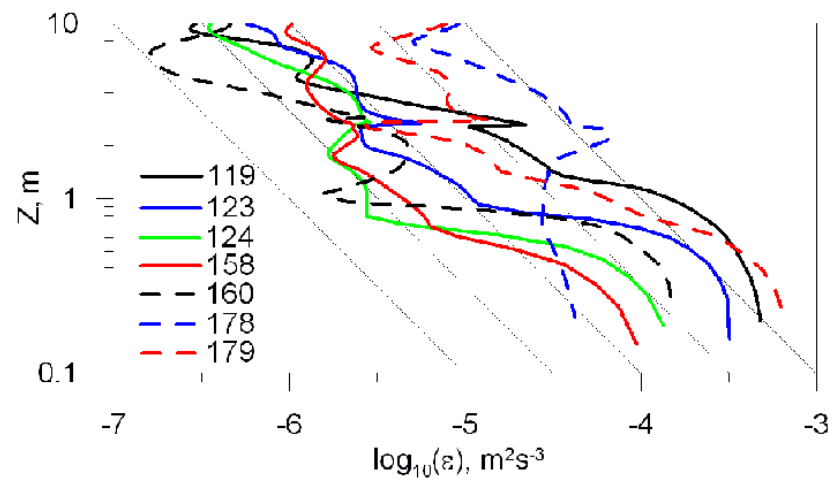

Fig. 8. A closeup of $\varepsilon$ versus $z$ in the near-bottom layer (the lowest $10 \mathrm{~m}$ ) for a number of stations when the microstructure sonde reached the sea floor. Numbers on the panel are the station numbers. Thin straight-line segments with a slope of -1 are the theoretical curves given by Eq. (11).

Using the MSP and LADCP data, we calculated the bulk parameters of the gravity current $(U, B$, and $H)$ as well as the entrainment rate $w_{\mathrm{e}}$. Finally, we arrived at the nondimensional parameters - the entrainment ratio, $E$, and the Froude number, $F r$, defined as

$E=\frac{w_{\mathrm{e}}}{U}, F r=\frac{U}{(B H)^{1 / 2}}$.

Parameters $U, B, H, w_{\mathrm{e}}$ (calculated using either Eqs. (16) or Eq. (7) along with the assumption of a linear growth of the buoyancy flux $K_{\rho} N^{2}$ with $z$ in the bottom mixed layer), $E$, and $F r$ calculated for each station are given in Table 1. First of all, one can see from the table that the Eqs. (1-6) approach usually results in more than an order of magnitude smaller values of $w_{\mathrm{e}}$ than that using Eq. (7) $\left(w_{\mathrm{e}}=(1.3-6.7) 10^{-6} \mathrm{~m} \mathrm{~s}^{-1}\right)$ versus $w_{\mathrm{e}}=5.210^{-6}$ $\left.1.3210^{-4} \mathrm{~m} \mathrm{~s}^{-1}\right)$. A similar mismatch can be found in the microstructure estimates of entrainment rate obtained in the Arkona Basin of the Baltic Sea (Arneborg et al., 2007; Umlauf and Arneborg, 2009): the approach (Eq. 7) brought $w_{\mathrm{e}}=4.8 \times 10^{-6}-7.5 \times 10^{-5} \mathrm{~m} \mathrm{~s}^{-1}$ (Arneborg et al., 2007), while Umlauf and Arneborg (2009) reported $w_{\mathrm{e}}=$ $2.1 \times 10^{-6} \mathrm{~m} \mathrm{~s}^{-1}$ applying the approach (Eqs. 1-6) to the same data set. As we have already mentioned, estimates of entrainment obtained using the Osborn (1980) and Shih et al. (2005) parameterizations of eddy diffusivity can be considered as the upper and lower limits, respectively.

The MSP and LADCP measurements presented in Table 1 refer to 17 stations located at two points downstream of the DS sill: one at a sea depth $\sim 1760 \mathrm{~m}$ (St. 123-124), and a second at $\sim 1450 \mathrm{~m}$ (the remaining stations). The gravity current at the $1450 \mathrm{~m}$ site was highly variable $(U=0.33-$ $0.91 \mathrm{~m} \mathrm{~s}^{-1}$ ), likely due to cyclonic eddy activity. The mean values of the entrainment ratio, obtained from Eqs. (1-5) and Eq. (7) accordingly, and the Froude number for these two sites are $E=3.610^{-6}$ and $5.010^{-5}, F r=0.89$ (for the 
$1450 \mathrm{~m}$ site) and $E=2.310^{-5}$ and $3.610^{-4}, F r=0.80$ (for the $1760 \mathrm{~m}$ site).

Figure 7 is a reproduction of Fig. 2 by Wells et al. (2010) representing an empirical dependence of the entrainment ratio $E$ versus Froude number $\mathrm{Fr}$ collected from different field and laboratory experiments. We have added two pairs of extra points in this figure that came from this study (the red and magenta pentagons). To our mind, these new estimates of $E$ and $\mathrm{Fr}$ fit well with the general tendency seen in Fig. 7.

\subsection{Microstructure estimates of bottom and interfacial stresses}

We apply the law of the wall

$u_{z}=\frac{u_{*}}{\kappa z}$

and a stationary balance of kinetic energy of turbulence in the form

$-\left\langle u^{\prime} w^{\prime}\right\rangle u_{z}=\varepsilon+\frac{g}{\rho_{0}}\left\langle\rho^{\prime} w^{\prime}\right\rangle+\frac{1}{\rho_{0}} \frac{\partial\left\langle p^{\prime} w^{\prime}\right\rangle}{\partial z}$,

where the prime denotes a fluctuation of a velocity component, pressure, or density, and $\kappa=0.4$ is the von Kármán constant, within the near-bottom constant stress layer $\left(-\left\langle u^{\prime} w^{\prime}\right\rangle=u_{*}^{2}=\right.$ const $)$. Taking into account that the buoyancy flux vanishes at the sea floor $\left(\left\langle\rho^{\prime} w^{\prime}\right\rangle \rightarrow 0\right.$ at $\left.z \rightarrow+0\right)$, and neglecting the vertical divergence of pressure flux, one can arrive at the relationship between $\varepsilon$ and $u_{*}$ :

$\varepsilon=\frac{u_{*}^{3}}{\kappa z}$.

Equation (11) forecasts an inverse $z$-dependence of $\varepsilon$ in the near-bottom constant stress layer, which can be verified by our microstructure measurements in the DSO plume.

Figure 8 presents a closeup of $\varepsilon$ versus $z$ in a $10 \mathrm{~m}$ thick near-bottom layer for a number of stations where the microstructure sonde reached the sea floor. Despite considerable irregularities, the plots clearly display an inverse power-like $z$-dependence of dissipation rate, $\varepsilon \sim z^{-\alpha}$, with $\alpha$ roughly estimated within the range of $0.7-2$. In view of Eq. (11) and Fig. 8, we propose that the friction velocity at the bottom, $u_{*}$, can be estimated as the mean value of $(\kappa z \varepsilon)^{1 / 3}$ in a $10 \mathrm{~m}$-thick near-bottom layer, or:

$u_{*}=\left\langle(\kappa z \varepsilon)^{1 / 3}\right\rangle_{z \leq 10 \mathrm{~m}}$.

Estimates of $u_{*}$ obtained through Eqs. (11-12) are given in Table 1 . They vary in the range of $u_{*}=0.012-$ $0.029 \mathrm{~m} \mathrm{~s}^{-1}$, so that respective values of drag coefficient, $C_{\mathrm{d}}=\left(u_{*} / U\right)^{2}$, are confined within the generally accepted range of $C_{\mathrm{d}}=(0.9-3.0) 10^{-3}$, with a mean value and standard deviation of $\left\langle C_{\mathrm{d}}\right\rangle=(1.83 \pm 0.82) 10^{-3}$. If the drag coefficient is defined as $C_{\mathrm{d}}=\left(u_{*} / U_{\max }\right)^{2}$, where $U_{\max }$ is the

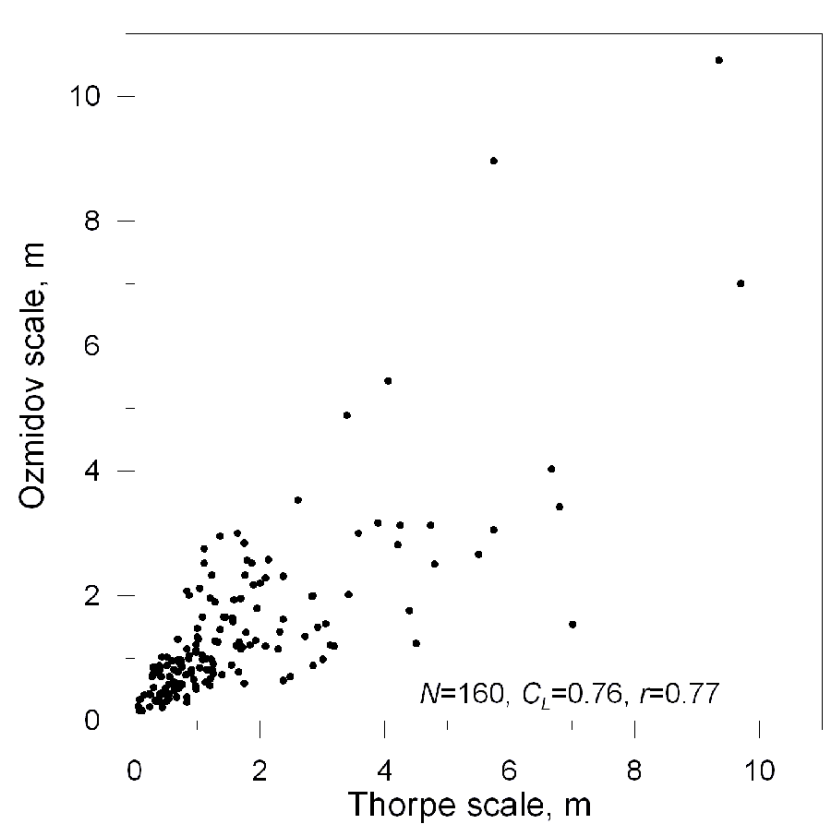

Fig. 9. Ozmidov scale versus Thorpe scale in the interfacial layer.

maximum value of the overflow velocity at a given station (as was done by Johnson et al., 1994a, b), it will be confined to the range of $C_{\mathrm{d}}=(0.58-1.9) 10^{-3}$, with a mean value of $\left\langle C_{\mathrm{d}}\right\rangle=(1.07 \pm 0.46) 10^{-3}$.

The interfacial stress retarding the plume due to entrainment, $\tau_{\mathrm{e}}$, can be written as (Phillips, 1977)

$\tau_{\mathrm{e}}=\rho_{0} w_{\mathrm{e}} U$,

and the interfacial friction velocity, $u_{* e}=\sqrt{\tau_{\mathrm{e}} / \rho_{0}}$ becomes

$u_{* e}=\sqrt{w_{\mathrm{e}} U}$.

Calculations presented in Table 1 show that the interfacial stress estimated using Eqs. (1-5) and (14) is mostly more than an order of magnitude smaller than the bottom stress estimated from dissipation profiles in the DSO plume.

Obtained values of $u_{*}$ are worth comparing with similar estimates by Johnson et al. (1994a) and Umlauf and Arneborg (2009) based on application of (Eq. 11) to microstructure measurements of dissipation profiles in ocean overflow plumes. Umlauf and Arneborg (2009) reported $u_{*}=0.011 \mathrm{~m} \mathrm{~s}^{-1}$ in a saline water overflow in the Baltic Sea, while Johnson et al. (1994a) reported $u_{*}=0.004$ $0.062 \mathrm{~m} \mathrm{~s}^{-1}$ in the Mediterranean outflow plume. It is remarkable that our estimate of the drag coefficient based on dissipation measurements, $\left\langle C_{\mathrm{d}}\right\rangle=\left\langle u_{*}^{2} / U_{\max }^{2}\right\rangle=(1.07 \pm 0.46$ ) $10^{-3}$, is close to that of Johnson et al. (1994a) $C_{\mathrm{d}}=(0.8 \pm 0.2) 10^{-3}$. Note that in the notation of Johnson et al. (1994a and $b$ ), the number next to \pm is twice the standard error of the mean, while in ours it is the standard deviation of the mean. To our mind, the latter statistic is more universal, containing "pure" information about the scatter of empirical 
estimates of a quantity regardless of the nature of the scatter, while the former makes sense only if the very quantity is believed to be constant and the scatter is due to measurement inaccuracy.

Johnson et al. (1994a) reported that $C_{\mathrm{d}}$ obtained from dissipation measurements in the Mediterranean outflow plume and Eq. (11) is a factor of 3 smaller than that of velocity measurements and the law of the wall (Eq. (9)). Moreover, Dewey and Crawford (1988) found a factor of 4.5 between stress estimates on the continental shelf from dissipation and from velocity data. Unfortunately, the LADCP data obtained in the DSO plume along with the dissipation data are not suitable for estimating the stress in the bottom layer using the log model, because the closest-to-bottom velocity reading of no less than $70 \%$ of the maximum velocity was taken approx. $30 \mathrm{~m}$ above the bottom (see Figs. 5 and 6), which is undoubtedly outside the constant stress bottom layer. However, we may use for comparison an estimate of drag coefficient of $C_{\mathrm{d}}=(2.9 \pm 0.4) 10^{-3}$, obtained in the DSO plume from velocity (XCP) profiles (Girton and Sanford, 2003), which exceeds our dissipation-based estimate by a factor of 2.7. Note that the value of drag coefficient in ocean overflows is highly variable and may be much larger than 0.003; direct measurements of the Reynolds stress in the Red Sea outflow plume (Peters and Johns, 2006) found $C_{\mathrm{d}}$ as large as $0.008-0.009$ at one location.

Johnson et al. (1994a) considered five possible reasons for the discrepancy between bottom stress estimates, $\tau_{\varepsilon}$ and $\tau_{\mathrm{s}}$, derived from dissipation and velocity data, respectively. (a) Form drag over the rough bottom could be important within the boundary layer, such that $\tau_{\varepsilon}$ would underestimate the real bottom stress. Form drag produces pressure and velocity anomalies, and vertical divergence of these anomalies (the third term in the right hand side of Eq. (10)) is a local sink for turbulent kinetic energy, just like dissipation. (b) Internal (downstream) pressure gradients might cause von Kármán's constant to decrease from the value used, affecting the ratio and the absolute magnitudes of the two stress estimates, inflating $\tau_{\varepsilon}$ over $\tau_{\mathrm{s}}$ (in view of Eqs. (9) and (12)). (c) Partial geostrophic balance in the boundary layer is not taken into account in calculating $\tau_{\mathrm{s}}$, and may also inflate it (transverse circulation in the plume produces horizontal gradients of density and, therefore, provides the geostrophic reduction in downstream velocity toward the bottom (MacCready and Rhines, 1993), complementary to the shear supported by stress. (d) Neglecting buoyancy flux within the bottom boundary layer may reduce $\tau_{\varepsilon}$. (e) The $\tau_{\varepsilon}$ may underestimate the stress due to undersampling of intermittent dissipation within the boundary layer. Johnson et al. (1994a) concluded eventually that the local bottom stresses estimated from velocity profiles are closer to the actual mean bottom stresses than those from the dissipation measurements.

Therefore, we believe that, similar to the Mediterranean outflow plume, our dissipation-derived values underestimate the real values of bottom stress and drag coefficient in the DSO plume by a factor of approximately 3 .

\subsection{Ozmidov scale vs. Thorpe scale}

In highly energetic turbulent stratified flows like the DSO, there is a possibility of quantifying turbulent mixing on the basis of overturning scales extracted from conventional CTD data. Thorpe (1977) first showed how to extract a turbulence length scale from potential density profiles $\rho_{\theta}(z)$, or, in the case of freshwater, from potential temperature profiles $\theta(z)$. Sorting discrete profiles of either $\rho_{\theta}(z)$ or $\theta(z)$ into monotonic sequences is associated with vertically displacing water parcels by the turbulent displacement distance, $\varsigma$. The Thorpe scale, $L_{\mathrm{Th}}$, is defined as the rms of $\varsigma: L_{\mathrm{Th}}=\left\langle\varsigma^{2}\right\rangle^{1 / 2}$, and can be interpreted as the size of the largest turbulent eddies that can exist in a stratified flow, given that they have finite kinetic energy and therefore can only do finite work against buoyancy forces (Dillon, 1982). The same physical sense has previously been attributed to the Ozmidov scale, $L_{\mathrm{O}} \equiv \varepsilon^{1 / 2} N^{-3 / 2}$ (Ozmidov, 1965). Dillon (1982) and many later studies confirm that, on average,

$L_{\mathrm{O}}=C_{\mathrm{L}} L_{\mathrm{Th}}$,

where $C_{\mathrm{L}}$ is often taken as a constant close to 1 (Crawford 1986; Dillon and Park 1987; Peters et al., 1995). Given the validity of Eq. (15) with $C_{\mathrm{L}}=1$, Peters and Johns (2005) estimated turbulent dissipation rates, vertical turbulent salt flux, and interfacial stress in the Red Sea outflow plume from conventional CTD data and thereby quantified interfacial mixing.

Since the DSO plume is not characterized by any sizeable level of thermoclinicity, which makes the formation of potential temperature inversions by lateral intrusions improbable, one can use potential temperature instead of potential density to calculate the Thorpe scale, thereby avoiding false inversions in CTD-derived $\rho_{\theta}(z)$ arising from the mismatch of temperature and conductivity sensor response times. In this study, the Thorpe and Ozmidov scales were calculated from MSP data as the running average in approximately $20 \mathrm{~m}$ vertical bins providing statistical estimates of $\left\langle\varsigma^{2}\right\rangle^{1 / 2}$ in the range of $\left\langle\varsigma^{2}\right\rangle^{1 / 2} \leq 10 \mathrm{~m}$ with the number of degrees of freedom $\geq 2$.

The Ozmidov scale versus the Thorpe scale calculated in the interfacial layer of the DSO plume from MSP data is plotted in Fig. 9. To produce the plot, we made use of microstructure measurements in stations with a wide interfacial layer only (like that of St. 120 shown in Fig. 5a), where the whole layer allowed binning in several pieces of $20 \mathrm{~m}$-thick layers with more or less uniform gradients and fluctuation intensity. Given that the two fields, $L_{\mathrm{O}}$ and $L_{\mathrm{Th}}$, are derived from completely different estimates, they show a strikingly good correlation, with a correlation coefficient of $r=0.77$ and $C_{\mathrm{L}}=0.76$, where the latter value was obtained from a 
least squares fit. This fact greatly inspires confidence in the dissipation estimates extracted from the shear probe on the MSP.

\section{Discussion and conclusion}

Giving that the downstream decrease in the mean density of the plume, $d \overline{\rho_{\theta}} / d \xi<0$, where $\xi$ is the downstream distance from the sill, is due to the entrainment of ambient fluid, Girton and Sanford (2003) expressed the entrainment rate as

$w_{\mathrm{e}}=\frac{U H}{\overline{\rho^{\prime}}} \frac{d \overline{\rho_{\theta}}}{\mathrm{d} \xi}$,

where $\overline{\rho^{\prime}}<0$ is the density anomaly of entrained ambient water relative to the plume. Using data from XCP/XCTD/CTD profiling in the DSO plume in 1997-1998, they estimated the entrainment rate $w_{\mathrm{e}}$ at $410^{-5}$ and 8 $10^{-4} \mathrm{~m} \mathrm{~s}^{-1}$ before and after $\xi=125 \mathrm{~km}$. We note that our dissipation-derived estimates of $w_{\mathrm{e}}$ presented in Table 1 are 1-2 orders of magnitude smaller when derived from Eqs. (16) $\left(w_{\mathrm{e}}=(2.1 \pm 0.7) 10^{-6}\right.$ and $(6.7 \pm 0.1) 10^{-6} \mathrm{~m} \mathrm{~s}^{-1}$ in the 1450 and $1760 \mathrm{~m}$ sites, respectively), and a factor of 1.4-8.0 smaller when derived from Eq. (7) $\left(w_{\mathrm{e}}=(2.9 \pm 1.4) 10^{-5}\right.$ and $(1.0 \pm 0.4) 10^{-4} \mathrm{~m} \mathrm{~s}^{-1}$ in the 1450 and $1760 \mathrm{~m}$ sites, respectively) than bulk estimates from (Eq. 16). The entrainment rate at the $1760 \mathrm{~m}$ site is found to be a factor of 3 larger than that at the $1450 \mathrm{~m}$ site, likely due to a reduced thickness of the bottom mixed layer in the former (see Fig. 6), which is favorable for an increase of the share of turbulent kinetic energy generated by bottom friction to work against buoyancy forces rather than be dissipated by viscosity. Taking into account uncertainties in our estimates of $w_{\mathrm{e}}$, one may nevertheless suggest that the vertical turbulent mixing is not the major process controlling entrainment in the DSO plume at approx. $200 \mathrm{~km}$ from the sill, where our microstructure measurements were obtained.

A competitive process that can control entrainment is the lateral stirring of different water masses produced by mesoscale eddies. The DSO is known for its high variability on timescales of 1-12 days (Dickson and Brown, 1994). Pulses of strong current velocity are accompanied by domelike disturbances of the plume interface travelling with the velocity of the overflow plume. These cold water domes of $20-40 \mathrm{~km}$ in diameter are connected to mesoscale eddies reaching throughout the whole water column. These eddies have cyclonic rotation on the sea surface, and have been repeatedly observed in satellite altimetry (Høyer and Quadfasel, 2001) and infrared imagery (Bruce, 1995; Krauss, 1996). Using time series of currents and temperature in the DSO plume from moored instrumentation and classical hydrographic data, Voet and Quadfasel (2010) estimated lateral heat fluxes produced by fluctuations in temperature and cross-stream components of velocity on timescales of the mesoscale eddies. The lateral heat fluxes caused by mesoscale eddies were found to explain the observed downstream warming of the plume after $200 \mathrm{~km}$ from the sill. In view of the lack of data, the authors failed to estimate the lateral heat fluxes in the first $200 \mathrm{~km}$ from the sill, where the warming of the plume is a factor of 5 and larger and, therefore, the contribution of diapycnal mixing to entrainment is expected to be more essential. Since there are no dissipation data available in this range of distances, the question of the relative contribution of diapycnal and lateral mixing to entrainment remains open.

As pointed out by Hartmut Peters, a reviewer, there is another reason why bulk entrainment rates can be larger than local values derived from turbulence measurements. Nash et al. (2012) have pointed out the importance of small-scale features in the bottom topography. The flow appears to be hydraulically controlled at a small topographic constriction, with turbulence and internal waves varying together and increasing dramatically downstream of a choke point. Choke points for outflows can harbor turbulence, that is, orders of magnitude more intense than elsewhere; the turbulence mixing and entrainment can be concentrated in hotspots - as they are in the Mediterranean outflow.

A further explanation of the discrepancy between the dissipation and the bulk estimates of entrainment could be that the commonly cited bulk estimates are too high. The initial characteristics of the overflow plume are usually taken from the cold, dense, well-mixed deepest layer at the sill. However, several water masses contribute to the overflow, and the overflow plume is stratified (Rudels et al., 1999). Some of the observed downstream heating could then be due to the internal mixing between waters initially present in the plume, and not caused by entrainment of ambient water from south of the sill (Rudels et al., 1999).

Acknowledgements. The financial support for this study by the European Union 7th Framework Programme (FP7 2007-2013) under grant agreements No: 212643 THOR and No: 308299 NACLIM and the Russian Foundation for Basic Research (Grant \# 11-05-00718) is gratefully acknowledged. Leasing of $\mathrm{R} / \mathrm{V}$ MARIA S. MERIAN was paid for by the Scientific Foundation and the Ministry of Education and Research of Germany. We thank Hartmut Peters and an anonymous reviewer for stimulating discussions.

Edited by: N. Pinardi

\section{References}

Arneborg, L., Fiekas, V., Umlauf, L., and Burchard, H.: Gravity Current Dynamics and Entrainment - A Process Study Based on Observations in the Arkona Basin, J. Phys. Oceanogr., 37, 2094 2113, 2007.

Baringer, M. O. and Price, J. F.: Mixing and spreading of the Mediterranean Outflow. J. Phys. Oceanogr., 27, 1654-1677, 1997.

Bruce, J. G.: Eddies southwest of the Denmark Strait, Deep-Sea Res. Pt. I, 42, 13-29, 1995. 
Cenedese, C. and Adduce, C.: Mixing in a density-driven current flowing down a slope in a rotating fluid, J. Fluid Mech., 604, 369-388, 2008

Cenedese, C., Whitehead, J. A., Ascarelli, T. A., and Ohiwa, M.: A dense current flowing down a sloping bottom in a rotating fluid, J. Phys. Oceanogr., 34, 188-203, 2004.

Crawford, W. R.: A comparison of length scales and decay times of turbulence in stratified flows, J. Phys. Oceanogr., 16, 1847-1854, 1986.

Dallimore, C. J., Imberger, J., and Ishikawa, T.: Entrainment and turbulence in saline underflow in Lake Ogawara. J. Hydraul. Eng., 127, 937-948, 2001.

Dewey, R. K. and Crawford, W. R.: Bottom stress estimates from vertical dissipation rate profiles on the continental shelf, J. Phys. Oceanogr., 18, 1167-1177, 1988.

Dickson, R. R. and Brown, J.: The production of North Atlantic Deep Water: Sources, rates, and pathways, J. Geophys. Res., 99, 12319-12341, 1994.

Dillon, T. M.: Vertical overturns: A comparison of Thorpe and Ozmidov length scales, J. Geophys. Res., 87, 9601-9613, 1982.

Dillon, T. M. and Park, M. M.: The available potential energy of overturns as an indicator of mixing in the seasonal thermocline, J. Geophys. Res., 92, 5345-5353, 1987.

Ellison, T. H. and Turner, J. S.: Turbulent entrainment in stratified flows, J. Fluid Mech., 6, 423-448, 1959.

Fer, I., Voet, G., Seim, K. S., Rudels, B., and Latarius, K.: Intense mixing of the Faroe Bank Channel overflow, Geophys. Res. Lett., 37, L02604, doi:10.1029/2009GL041924, 2010.

Girton, J. B. and Sanford, T. B.: Descent and modification of the overflow plume in Denmark Strait, J. Phys. Oceanogr., 33, 13511364, 2003.

Høyer, J. L. and Quadfasel, D.: Detection of deep overflows with satellite altimetry, Geophys. Res. Lett., 28, 1611-1614, 2001.

Johnson, G. C., Lueck, R. G., and Sanford, T. B.: Stress on the Mediterranean outflow plume: Part II. Turbulent dissipation and shear measurements, J. Phys. Oceanogr., 24, 2084-2092, 1994a.

Johnson, G. C., Sanford, T. B., and Baringer, M. O.: Stress on the Mediterranean Outflow plume: Part I. Velocity and water property measurements, J. Phys. Oceanogr., 24, 2072-2083, 1994 b.

Krauss, W.: A note on overflow eddies, Deep-Sea Res. Pt. I, 43, 1661-1667, 1996.

Lueck, R. G., Wolk, F., and Yamazaki, H.: Oceanic velocity microstructure measurements in the $20^{\text {th }}$ century, J. Oceanogr., 58, 153-174, 2002.

Lynch, J. and Lueck, R.: Expendable dissipation profiler (XDP) data from the Mediterranean out-flow experiment: R/V Oceanus cruise 202 leg V. JHU-CBI TR89-01, The Johns Hopkins University, Chesapeake Bay Institute, Baltimore, MD, 284 pp., 1989.

MacCready, P. and Rhines, P. B.: Slippery bottom boundary layers on a slope, J. Phys. Oceanogr., 23, 5-22, 1993.

Mauritzen, C., Price, J. F., Sanford, T. B., and Torres, D.: Circulation and mixing in the Faroese Channels, Deep-Sea Res. I, 52, 883-913, 2005.

Nash, J. D., Peters, H., Kelly, S. M., Pelegrí, J. L., Emelianov, M., and Gasser, M.: Turbulence and high-frequency variability in a deep gravity current outflow, J. Geophys. Let., 39, L18611, doi:10.1029/2012GL052899, 2012.

Osborn, T.: Estimates of the local rate of vertical diffusion from dissipation measurements, J. Phys. Oceanogr., 10, 83-89, 1980.
Ozmidov, R. V.: On the turbulent exchange in a stably stratified ocean, Izv. Atmos. Ocean Phys., 1, 493-497, 1965.

Paka, V., Nabatov, V., Lozovatsky, I., and Dillon, T.: Oceanic microstructure measurements by "Baklan" and "Grif", J. Atmos. and Ocean Tech., 16, 519-1532, 1999.

Paka, V. T., Rudels, B., Quadfasel, D., and Zhurbas, V. M.: Measurements of Turbulence in the Zone of Strong Bottom Currents in the Strait of Denmark, Doklady Earth Sciences, 432, 613-617, 2010.

Peters, H., and Bokhorst R.: Microstructure observations of turbulent mixing in a partially mixed estuary. Part II: Salt flux and stress, J. Phys. Oceanogr., 31, 1105-1119, 2001.

Peters, H. and Johns, W. E.: Mixing and entrainment in the Red Sea Outflow plume. Part II: Turbulence characteristics, J. Phys. Oceanogr., 35, 584-600, 2005.

Peters, H. and Johns, W. E.: Bottom layer turbulence in the Red Sea Outflow plume, J. Phys. Oceanogr., 36, 1763-1785, 2006.

Peters, H., Gregg, M. C., and Sanford, T. B.: Detail and scaling of turbulent overturns in the Pacific Equatorial Undercurrent, J. Geophys. Res., 100, 18349-18368, 1995.

Phillips, O. M.: The Dynamics of the Upper Ocean, 2nd ed., Cambridge University Press, 336 pp., 1977.

Prandke, H., Holtsch, K., and Stips, A.: MITEC technology development: The microstructure/turbulence measuring system MSP. Tech. Rep., MITEC Hardware Report, EUR 19733EN, Space Application Institute, Joint Research Centre, European Commission, 64 pp., 2000.

Princevac, M., Fernando, H. J. S., and Whiteman, D. C.: Turbulent entrainment into natural gravity-driven flows, J. Fluid Mech., 33, 259-268, 2005.

Rudels, B., Eriksson, P., Grönvall, H., Hietala, R., and Launiainen, J.: Hydrographic observations in Denmark Strait in fall 1997, and their implications for the entrainment into the Overflow Plume, Geophys. Res. Letters, 26, 1325-1328, 1999.

Shih, L. H., Koseff, J. R., Ivey, G. N., and Ferziger, J. H.: Parameterization of turbulent fluxes and scales using homogeneous sheared stably stratified turbulence simulations, J. Fluid Mech., 525, 193 214, 2005.

Thorpe, S. A.: Turbulence and mixing in a Scottish loch, Philos. Trans. Roy. Soc. London, A286, 125-181, 1977.

Umlauf, L. and Arneborg, L.: Dynamics of rotating shallow gravity currents passing through a channel. Part I: Observation of transverse structure, J. Phys. Oceanogr., 39, 2385-2401, 2009.

Voet, G. and Quadfasel, D.: Entrainment in the Denmark Strait Overflow plume by meso-scale eddies, Ocean Sci., 6, 301-310, 2010 ,

http://www.ocean-sci.net/6/301/2010/.

Wells, M. G.: Influence of Coriolis forces on turbidity currents and sediment deposition. Particle-Laden Flow: From Geophysical to Kolmogorov Scales, B. J. Geurts, H. Clercx, and W. Uijttewaal, Eds., ERCOFTAC Series, Vol. 11, Springer, 331-343, 2007.

Wells, M., Cenedese, C., and Caulfield, C. P.: The Relationship between Flux Coefficient and Entrainment Ratio in Density Currents, J. Phys. Oceanogr., 40, 2713-2727, 2010.

Zhurbas V., Elken, J., Paka, V., Piechura, J., Chubarenko, I., Väli, G., Golenko, N., and Shchuka, S.: On the possibility of convective overturning in the Slupsk Furrow overflow of the Baltic Sea, Oceanologia, 53, 771-791, 2011. 